\title{
Estratégias de hedge com os contratos futuros de soja da Chicago Board of Trade
}

\author{
Hedging strategies with Chicago Board of \\ Trade soybeans futures contracts
}

\author{
Fábio Neves de Carvalho da Silva Maia ${ }^{1}$ \\ Danilo Rolim Dias de Aguiar ${ }^{2}$
}

\begin{abstract}
Resumo: Este trabalho avalia os retornos e os riscos de estratégias de hedge para as dez principais regiões produtoras de soja do Brasil em relação aos contratos futuros de soja da Chicago Board of Trade (CBOT). Verificou-se que as bases apresentaram padrão bem definido: fortalecimento entre maio e novembro, seguido por enfraquecimento nos seis meses subsequentes. Os hedgers de compra possuem oportunidades de obter retornos brutos maiores, mas os riscos envolvidos nas estratégias de hedge de compra também são maiores. Conclui-se que os contratos de soja em grão da CBOT apresentam diferentes possibilidades de retornos brutos em função do tipo de hedge, do período hedgeado e do contrato utilizado. Logo, as informações disponibilizadas neste trabalho se apresentam como importante subsídio ao processo de tomada de decisão por parte dos agentes da cadeia agroindustrial da soja.

Palavras-chave: Risco de preço. Soja. Hedge. Contratos futuros. Chicago Board of Trade.
\end{abstract}

\begin{abstract}
This paper analyzes the return and risks of hedging strategies of the major ten soybean producing regions in Brazil concerning Chicago Board of Trade (CBOT) future contracts. It was verified that the bases presented a well defined pattern characterized by strengthening from May to November and weakening in the remaining months. Long hedging had larger returns and larger risks comparing with short hedging. The conclusion of this study is that the CBOT soybean contracts present different returns depending on the type of hedging, on the period of hedging, and on the contract used. Therefore, the information presented in this paper is very important to support the decision making process in the Brazilian soybean agricultural system.
\end{abstract}

Keywords: Price risk. Soybeans. Hedging. Futures contracts. Chicago Board of Trade.

\section{Introdução}

O uso de estratégias de gerenciamento de risco de preço é de grande importância para produtores, processadores e traders que operam no mercado de soja, principalmente em função do elevado grau de volatilidade de preço desta commodity. No mercado nacional, dentre as principais commodities negociadas, a soja se destaca como sendo a segunda em nível de volatilidade, ficando atrás somente do café (AGUIAR, 2004). Neste contexto, o hedge com contratos futuros surge como alternativa das mais interessantes para os agentes que comercializam soja e derivados.

A bolsa de futuros mais importante é a Chicago Board of Trade (CBOT). Fundada em 1848, a CBOT, além de sua longa tradição em mercados futuros, é também a bolsa de referência para o comércio de soja, com mais de 20 milhões de contratos negociados por ano, o que faz deste mercado o de maior liquidez dentre os mercados futuros agrícolas. Tais características atraem traders de todas as partes do mundo, inclusive brasileiros, o que torna relevante avaliar a viabilidade de se utilizar o contrato da CBOT por parte dos hedgers localizados nas principais regiões do Brasil.

Operações de hedge consistem na adoção de uma carteira composta de uma posição no mercado físico e outra (oposta) no mercado futuro. Assim, ter-se-ia uma estratégia de hedge de venda quando um investidor comprasse ou produzisse o produto no mercado físico e vendesse contratos futuros. Por sua vez, operações de hedge de compra consistem na venda do produto no mercado à vista (se necessário), e na compra de contratos futuros. Dessa forma, como salienta Carter (2003), devido à correlação entre os preços à vista e futuro, variações de preço em um mercado tendem a ser, ao menos parcialmente, compensadas pelas variações do outro mercado. Portanto, o retorno

\footnotetext{
${ }^{1}$ Mestre em economia aplicada pela Universidade Federal de Viçosa (UFV). Bunge Açúcar e Bioenergia - Área de Planejamento e Controle Agrícola, Unidade Pedro Afonso - TO, E-mail: fabio.maia@ bunge.com

${ }^{2}$ Professor associado e Coordenador do Programa de Pós-Graduação em Economia da Universidade Federal de São Carlos, Campus de Sorocaba, Rodovia João Leme dos Santos, Km 110, CEP 18052-780, Sorocaba - SP, E-mail: danilo@ufscar.br
} Recebido em 22/2/2008 — Aceito em 7/4/2010

Suporte financeiro: Nenhum. 
bruto de uma operação de hedge é determinado pela variação dos preços ao longo do tempo.

Existem, basicamente, dois enfoques para se analisar operações de hedge. O primeiro se refere à mensuração da efetividade. Este enfoque se baseia na teoria do portfolio e analisa a correlação entre os preços à vista e futuro (CARTER, 2003). A outra abordagem se refere à análise do comportamento da diferença entre o preço à vista e o preço futuro, a chamada base.

Embora as abordagens da base e da efetividade sejam bastante distintas, elas conduzem a resultados complementares. Com o enfoque da efetividade consegue-se responder à questão da viabilidade ou não de se realizar a operação de hedge. Já a análise do comportamento da base permite identificar quando realizar a operação de hedge e qual é o retorno bruto esperado.

A maioria dos estudos sobre o mercado de futuro de soja realizados no Brasil tem utilizado a abordagem da efetividade do hedge, sendo exemplos destes os trabalhos de Silva, Aguiar e Lima (2003), Martins e Aguiar (2004) e Chiodi et al. (2005). Entre estes, destaca-se o trabalho de Martins e Aguiar (2004), que mostra que os contratos da CBOT com vencimento no segundo semestre se prestariam melhor a estratégias de hedge. Outros utilizaram o enfoque da base, como foi o caso de Barczsz e Alves (2002) e Fontes et al. (2005). Entretanto, nenhum desses trabalhos utilizou o enfoque da base para desenvolver instrumentos de tomada de decisão para hedgers localizados nas principais regiões produtoras e processadoras de soja no Brasil. Mesmo Dias e Figueiredo Neto (2008), que realizaram um estudo mais recente (envolvendo dados de 2005 a 2007), restringiram seu estudo a apenas quatro localidades e não especificaram quais contratos seriam melhores para cada tipo de estratégia.

Dessa forma, o objetivo geral deste trabalho é analisar, sob o enfoque da base, os retornos e os riscos da estratégia de hedge, utilizando os contratos futuros de soja em grão da CBOT, nas principais regiões produtoras do País. Com isso, pretende-se montar quadros e figuras auxiliares ao processo de tomada de decisão de hedgers. Especificamente, pretende-se: a) Definir os melhores momentos para a utilização de estratégias de hedge de compra e de venda, bem como os ganhos esperados com essas estratégias; b) calcular retornos e riscos esperados para cada uma das principais regiões do país; e (c) identificar a existência de algum padrão de comportamento que esteja presente em todas as localidades do País.

\section{Referencial teórico}

As relações de correlação e convergência dos preços à vista e das cotações futuras podem ser explicadas pela Lei do Preço Único. Em linhas gerais, esta lei postula que existe um preço para um produto (o preço à vista), e que qualquer dos outros preços é relacionado com aquele preço por meio dos custos de transporte e estocagem (BLANK; CARTER; SCHMIESING, 1991). Caso isto não ocorra, proverá aos arbitradores oportunidades lucrativas de intervenção no mercado. Pela ação desses arbitradores, as distorções dos preços à vista e as cotações futuras tendem a desaparecer (CARTER, 2003).

No entanto, em um mercado real, nem sempre todas as informações estão acessíveis aos agentes. Isto faz com que, em alguns momentos, possa haver movimentos da base de caráter excepcional e não previsíveis. Esses movimentos são responsáveis pelo chamado risco de base. Dessa forma, pode-se afirmar que operações de hedge consistem na troca do risco de preço pelo risco da base, sendo este último geralmente menor que o primeiro.

A mensuração do risco da base fornece uma medida de quão efetivos são os contratos futuros de diferentes vencimentos nas diversas regiões na atividade de gerenciamento do risco de preço, além de mostrar o quanto as informações históricas são eficientes na previsão do comportamento da base.

\section{Modelo analítico}

A base, definida anteriormente, pode ser expressa como na Equação 1:

$$
B_{t(t+n), i}=V_{t, i}-F_{t(t+n)}
$$

em que:

$B_{t(t+n), i}=$ base no momento $\mathrm{t}$, em relação ao contrato com vencimento em $(\mathrm{t}+\mathrm{n})$ para a localidade $i$;

$\mathrm{V}_{t, i}=$ preço à vista em $\mathrm{t}$, na localidade $i ; \mathrm{e}$

$F_{t(t+n)}^{t, i}=$ preço, no momento $t$, do contrato futuro com vencimento em $(t+n)$.

Lembrando que uma operação de hedge de venda consiste em comprar o produto no mercado à vista num primeiro momento e vendê-lo em um segundo momento, enquanto no mercado futuro, inicialmente, vendem-se contratos futuros de determinado vencimento para, em um segundo momento, comprá-los, a Equação 2 mostra o retorno bruto de uma operação de hedge de venda.

$$
R h v=\left(V_{2}-V_{1}\right)+\left(F_{1}-F_{2}\right)
$$

em que:

$R h v=$ retorno bruto esperado no hedge de venda;

$V_{2}=$ preço à vista esperado para o período 2 ;

$V_{1}=$ preço à vista no período 1 ;

$F_{2}=$ preço futuro esperado para o período 2 ; e

$F_{1}=$ preço futuro no período 1 .

Alterando a ordem das variáveis, pode-se expressar o retorno bruto de um hedge de venda em termos da base Equação 3:

$$
R h v=\left(V_{2}-F_{2}\right)-\left(V_{1}-F_{1}\right)=B_{2}-B_{1}
$$


em que:

$B_{1}=$ base observada no período 1 ; e

$B_{2}=$ base esperada no período 2 .

A Equação (3) mostra que o retorno bruto de uma operação de hedge de venda será positivo caso a base no momento 2 seja maior que a base no momento 1 . Este movimento de base denomina-se fortalecimento; portanto, fortalecimentos da base configuram retornos brutos positivos a hedgers de venda.

Considerando-se um hedge de compra, ter-se-ia Equação 4:

$$
R h c=\left(V_{1}-V_{2}\right)-\left(F_{2}-F_{1}\right)
$$

Alterando a ordem das variáveis, ter-se-ia Equação 5:

$$
\begin{aligned}
& R h c=\left(V_{1}-F_{1}\right)-\left(V_{2}-F_{2}\right) \Rightarrow \\
& \Rightarrow R h c=B_{1}-B_{2}
\end{aligned}
$$

A Equação 5 mostra que operações de hedge de compra apresentam retorno bruto positivo caso a base no momento 1 seja maior que a base no momento 2 . Este tipo de movimento da base é denominado enfraquecimento da base e corresponde a retornos brutos positivos aos hedgers de compra.

Dessa forma, tem-se que fortalecimentos da base fornecem retornos brutos positivos aos hedgers de venda e negativos aos hedgers de compra, enquanto enfraquecimentos da base causam retornos brutos positivos aos hedgers de compra e negativos aos hedgers de venda.

Outra questão relevante para se avaliar a base é o seu risco. Segundo Fileni (1999), o risco de base é usualmente quantificado pela variância ou desviopadrão durante o período. Porém, para assegurar a comparabilidade dos resultados, como sugere Houthakker e Williamson (1996), o risco da base, que caracteriza o risco do hedge, será representado pelo coeficiente de variação, e estes termos serão usados como sinônimos. O coeficiente de variação, obtido pela divisão do desvio-padrão pela média das variações mensais da base, não depende das unidades de medida, sendo o indicador mais simples do risco relativo de diferentes investimentos.

\section{Estratégia empírica}

A análise do comportamento da base das várias regiões brasileiras em relação aos contratos de soja em grão da CBOT abrangeu os anos de 2001 a 2004. Os municípios escolhidos para este estudo foram: Balsas, Maranhão; Barreiras, Bahia; Sorriso, Mato Grosso; Rio Verde, Goiás; Uberlândia, Minas Gerais; Dourados, Mato Grosso do Sul; Cândido Mota, São Paulo; Cascavel, Paraná; Passo Fundo, Rio Grande do Sul; e Chapecó, Santa Catarina. A escolha dos municípios visou abranger todas as regiões produtoras de soja. Assim, eles foram escolhidos devido a sua importância regional.

Os dados das cotações diárias dos preços foram obtidos junto à FNP consultoria. De posse dos dados, foram calculadas as bases diárias dos diferentes vencimentos para cada região. A partir desta série, procedeu-se ao cálculo da média mensal das bases para cada um dos quatro anos e, posteriormente, foi calculada a base média mensal envolvendo os quatro anos da análise. O risco de base foi mensurado pelo coeficiente de variação, que é o desvio-padrão dividido pela média das variações mensais da base.

Na mensuração da base média mensal, foi utilizado o maior período disponível, no qual houve negociação do contrato, desde que fosse possível o cálculo envolvendo as quatro médias.

\section{Análise e discussão dos resultados}

Esta seção inicia-se com os resultados referentes a cada localidade (item 5.1) e é concluída com uma análise conjunta (item 5.2), em que são buscados padrões mais gerais de comportamento que se apliquem às várias localidades. Com isso, é possível saber quais são os melhores contratos futuros (ou seja, quais os melhores vencimentos) a serem usados para cada tipo de operação (hedge de compra ou hedge de venda) para cada localidade. É também possível identificar o período de duração ideal de cada operação e o risco que estaria associado a cada operação.

\subsection{Estratégias de Hedge para cada localidade}

Esta parte do trabalho avalia os retornos e os riscos para hedgers localizados em cada uma das principais regiões produtoras do País, em relação a cada vencimento do contrato futuro. Dessa forma, são formulados quadros que permitem identificar os retornos médios e os riscos esperados, dependendo do momento de estabelecimento do hedge, do vencimento do contrato futuro escolhido e do tempo de duração da operação.

Os quadros mostram a variação da base (retorno médio) em cada período mensal (janeiro a fevereiro; fevereiro a março; março a abril etc.), em relação ao preço à vista da localidade e à cotação do contrato futuro para cada um dos vencimentos (janeiro, março, maio, julho, agosto, setembro e novembro).

\subsubsection{Região de Balsas}

O Quadro 1 apresenta os valores da variação mensal da base, além do risco da base, considerando todo o período de negociação dos contratos. A melhor estratégia disponível a um hedger de compra dessa região seria a utilização do contrato de julho, entre os meses de novembro e maio, sendo possível um 
retorno bruto de US\$2,02/sc. O risco de base para essa operação em específico foi estimado em 0,65. Para um hedger de venda, a melhor oportunidade de receita bruta seria o contrato de novembro, entre os meses de março e outubro, sendo o retorno bruto esperado de tal operação de US\$ $0,67 /$ sc. O risco de base associado a essa operação é de 0,41. A diferença de rentabilidade para os dois tipos de hedgers nesse caso é de, aproximadamente, $200 \%$, indicando que operações de hedge de compra oferecem maiores retornos brutos que estratégias de hedge de venda.

\subsubsection{Região de Barreiras}

Na região de Barreiras, o processo de enfraquecimento da base se estende até o mês de maio. Para esse tipo de operação, o período que permite auferir o maior retorno bruto é o intervalo de meses de novembro a maio, utilizando o contrato de julho. O retorno bruto esperado é de US\$2,33/sc, e o risco de base foi estimado em 0,54. A melhor estratégia de hedge de venda envolve o uso do contrato de janeiro entre os meses de setembro e dezembro. O retorno bruto previsto é US\$ $0,59 / \mathrm{sc}$; por sua vez, o risco de base calculado foi de 0,38 (Quadro 2).

\subsubsection{Região de Sorriso}

A região de Sorriso destacou-se como sendo a região de menor risco de base. No caso do período de enfraquecimentos, que nessa região ocorre de novembro a março, e o contrato que mais se destaca também é o de julho. Entre os meses de novembro e março, a receita bruta prevista é de US\$ 2,17/ sc, com um risco de base de 0,46 . O processo de fortalecimento da base, embora seja novamente em menor escala que o enfraquecimento, destaca-se frente às outras regiões. $\mathrm{O}$ contrato de setembro, embora apresente enfraquecimentos ao longo de sua vigência, é a melhor alternativa ao hedgers de venda. No período de março a agosto, o retorno bruto esperado é de US $\$ 1,21 / \mathrm{sc}$, com um risco de base de 0,20 (Quadro 3).

\subsubsection{Região de Rio Verde}

O Quadro 4 apresenta as variações do comportamento da base ao longo do ano na região de Rio Verde. Como nas demais regiões, o contrato de julho é o que oferece o maior retorno bruto aos hedgers de compra. No intervalo de meses de novembro a maio o retorno bruto esperado é de US\$ $2,40 / \mathrm{sc}$, e o risco de base associado a essa estratégia é de 0,59. No caso dos hedgers de venda, o contrato de janeiro seria o de maior rentabilidade, principalmente se utilizado no período de agosto a novembro. $\mathrm{O}$ retorno bruto seria de US\$ $0,89 / \mathrm{sc}$, com um risco de base de 0,42 .

\subsubsection{Região de Uberlândia}

O Quadro 5 apresenta as variações mensais da base dos contratos de soja da CBOT para a região de Uberlândia. O processo de enfraquecimento da base é muito intenso nessa região. $\mathrm{O}$ contrato de julho, entre os meses de dezembro e maio, pode proporcionar um retorno bruto de US $\$ 2,45 / \mathrm{sc}$, com um risco de

Quadro 1. Variações mensais da base (US\$/sc) em relação ao contrato futuro de soja da CBOT para a Região de Balsas com diferentes vencimentos. Média de 4 anos (2001 a 2004).

\begin{tabular}{|lccccccc|}
\hline \multicolumn{1}{|c}{ Meses } & \multicolumn{7}{c|}{ Contratos } \\
\cline { 2 - 8 } & Janeiro & Março & Maio & Julho & Agosto & Setembro & Novembro \\
\hline Janeiro-Fevereiro & - & $-0,79$ & $-0,79$ & $-0,74$ & $-0,75$ & $-0,40$ & - \\
Fevereiro-Março & - & - & $-0,69$ & $-0,72$ & $-0,66$ & $-0,46$ & - \\
Março-Abril & - & - & 0,07 & 0,06 & 0,15 & 0,37 & 0,36 \\
Abril-Maio & - & - & - & $-0,18$ & $-0,18$ & $-0,21$ & $-0,25$ \\
Maio-Junho & - & - & - & 0,25 & 0,28 & 0,24 & 0,17 \\
Junho-Julho & - & - & - & - & 0,28 & 0,25 & 0,16 \\
Julho-Agosto & - & - & - & - & - & 0,02 & $-0,13$ \\
Agosto-Setembro & $-0,16$ & - & - & - & - & - & 0,21 \\
Setembro-Outubro & 0,09 & 0,09 & - & - & - & - & 0,14 \\
Outubro-Novembro & 0,22 & 0,22 & 0,18 & 0,20 & - & - & - \\
Novembro-Dezembro & $-0,08$ & $-0,12$ & $-0,19$ & $-0,13$ & - & - & - \\
Dezembro-Janeiro & - & $-0,11$ & $-0,20$ & $-0,32$ & $-0,15$ & - & - \\
Variação Total & 0,07 & $-0,71$ & $-1,62$ & $-1,57$ & $-1,02$ & $-0,19$ & 0,67 \\
Risco da Base & 0,51 & 0,57 & 0,68 & 0,63 & 0,55 & 0,43 & 0,41 \\
\hline
\end{tabular}

Fonte: Resultados da Pesquisa. 
base de 0,63. Para hedgers de venda, o retorno bruto situa-se na média do que foi mensurado nas outras regiões. O contrato de janeiro pode proporcionar um retorno bruto de US\$ 0,96/sc. A esse retorno é associado um risco de base de 0,59.

\subsubsection{Região de Dourados}

O comportamento de base na região de Dourados, exposto no Quadro 6, mostra que o processo de enfraquecimento da base se estende até março. Para hedgers interessados nesse tipo de operação, a preferência deve ser dada ao contrato de julho, o maior retorno bruto passível de ser alcançado é US\$ 2,52/sc. O risco de tal operação é de 0,86 . Destaca-se que esse foi o terceiro maior retorno bruto mensurado neste trabalho. Já operações de hedge de venda apresentaram um retorno bruto dentro da média das outras regiões. $\mathrm{O}$ contrato de

Quadro 2. Variações mensais da base (US\$/sc) e o risco da base em relação ao contrato futuro de soja da CBOT para a Região de Barreiras com diferentes vencimentos. Média de 4 anos (2001 a 2004).

\begin{tabular}{|lccccccc|}
\hline \multicolumn{1}{|c}{ Meses } & \multicolumn{7}{c}{ Contratos } \\
\cline { 2 - 8 } & Janeiro & Março & Maio & Julho & Agosto & Setembro & Novembro \\
\hline Janeiro-Fevereiro & - & $-0,94$ & $-0,93$ & $-0,88$ & $-0,89$ & $-0,63$ & - \\
Fevereiro-Março & - & - & $-0,13$ & $-0,17$ & $-0,11$ & 0,09 & - \\
Março-Abril & - & - & $-0,03$ & $-0,04$ & 0,05 & 0,26 & 0,14 \\
Abril-Maio & - & - & - & $-0,31$ & $-0,30$ & $-0,33$ & $-0,37$ \\
Maio-Junho & - & - & - & 0,13 & 0,16 & 0,12 & 0,05 \\
Junho-Julho & - & - & - & - & 0,09 & 0,07 & $-0,01$ \\
Julho-Agosto & - & - & - & - & - & 0,26 & 0,11 \\
Agosto-Setembro & $-0,15$ & - & - & - & - & - & 0,11 \\
Setembro-Outubro & 0,19 & 0,24 & - & - & - & - & 0,19 \\
Outubro-Novembro & 0,36 & 0,37 & 0,32 & 0,35 & - & - & - \\
Novembro-Dezembro & 0,03 & $-0,02$ & $-0,09$ & $-0,04$ & - & - & - \\
Dezembro-Janeiro & - & $-0,71$ & $-0,78$ & $-0,89$ & $-0,70$ & - & - \\
Variação Total & 0,44 & $-1,05$ & $-1,64$ & $-1,84$ & $-1,70$ & $-0,16$ & 0,22 \\
Risco da Base & 0,34 & 0,53 & 0,59 & 0,54 & 0,44 & 0,27 & 0,22 \\
\hline
\end{tabular}

Fonte: Resultados da Pesquisa.

Quadro 3. Variações mensais da base (US\$/sc) em relação ao contrato futuro de soja da CBOT para a Região de Sorriso com diferentes vencimentos. Média de 4 anos (2001 a 2004).

\begin{tabular}{|lccccccc|}
\hline \multicolumn{1}{|c}{ Meses } & \multicolumn{7}{c|}{ Contratos } \\
\cline { 2 - 8 } & Janeiro & Março & Maio & Julho & Agosto & Setembro & Novembro \\
\hline Janeiro-Fevereiro & - & $-1,17$ & $-1,17$ & $-1,11$ & $-1,12$ & $-0,87$ & - \\
Fevereiro-Março & - & - & $-0,36$ & $-0,40$ & $-0,34$ & $-0,13$ & - \\
Março-Abril & - & - & 0,20 & 0,19 & 0,28 & 0,50 & 0,28 \\
Abril-Maio & - & - & - & $-0,12$ & $-0,11$ & $-0,14$ & $-0,18$ \\
Maio-Junho & - & - & - & 0,48 & 0,51 & 0,47 & 0,40 \\
Junho-Julho & - & - & - & - & 0,16 & 0,13 & 0,06 \\
Julho-Agosto & - & - & - & - & - & 0,25 & 0,10 \\
Agosto-Setembro & $-0,09$ & - & - & - & - & - & 0,10 \\
Setembro-Outubro & 0,17 & 0,21 & - & - & - & - & 0,17 \\
Outubro-Novembro & 0,01 & 0,01 & $-0,03$ & 0,00 & - & - & - \\
Novembro-Dezembro & 0,01 & $-0,03$ & $-0,11$ & $-0,05$ & - & - & - \\
Dezembro-Janeiro & - & $-0,42$ & $-0,50$ & $-0,61$ & $-0,44$ & - & - \\
Variação Total & 0,11 & $-1,40$ & $-1,96$ & $-1,62$ & $-1,05$ & 0,20 & 0,93 \\
Risco da Base & 0,22 & 0,38 & 0,42 & 0,41 & 0,32 & 0,21 & 0,24 \\
\hline
\end{tabular}

Fonte: Resultados da Pesquisa. 
novembro, quando utilizado no intervalo dos meses de julho a outubro, pode retornar US\$ 0,86 , com um risco de base de 0,38.

\subsubsection{Região de Cândido Mota}

A região de Cândido Mota apresenta como diferencial um processo de enfraquecimento da base intenso e contínuo para quase todos os contratos. Esse processo inicia-se em novembro e se estende até maio.
O contrato de julho apresenta, quando utilizado de novembro a maio, um retorno bruto de US\$2,68/sc, com um risco de base de 1,27. Essa região destaca-se, além das altas rentabilidades esperadas, pelos valores mais elevados do risco de base (Quadro 7).

As operações de hedge de venda praticamente só seriam viáveis por meio do uso dos contratos de janeiro e de novembro. Destes, o de novembro é o que apresenta maior capacidade de retorno bruto, US\$1,02/sc, e risco de base de 1,51 (Quadro 7).

Quadro 4. Variações mensais da base (US\$/sc) em relação ao contrato futuro de soja da CBOT para a Região de Rio Verde com diferentes vencimentos. Média de 4 anos (2001 a 2004).

\begin{tabular}{|lccccccc|}
\hline \multicolumn{1}{|c}{ Meses } & \multicolumn{7}{c|}{ Contratos } \\
\cline { 2 - 8 } & Janeiro & Março & Maio & Julho & Agosto & Setembro & Novembro \\
\hline Janeiro-Fevereiro & - & $-0,77$ & $-0,77$ & $-0,71$ & $-0,72$ & $-0,47$ & - \\
Fevereiro-Março & - & - & $-0,75$ & $-0,79$ & $-0,73$ & $-0,52$ & - \\
Março-Abril & - & - & $-0,01$ & $-0,02$ & 0,07 & 0,29 & 0,16 \\
Abril-Maio & - & - & - & $-0,27$ & $-0,26$ & $-0,30$ & $-0,34$ \\
Maio-Junho & - & - & - & 0,27 & 0,30 & 0,26 & 0,20 \\
Junho-Julho & - & - & - & - & 0,05 & 0,02 & $-0,06$ \\
Julho-Agosto & - & - & - & - & - & $-0,02$ & $-0,17$ \\
Agosto-Setembro & 0,08 & - & - & - & - & - & 0,46 \\
Setembro-Outubro & 0,60 & 0,62 & - & - & - & - & 0,49 \\
Outubro-Novembro & 0,21 & 0,21 & 0,14 & 0,17 & - & - & - \\
Novembro-Dezembro & $-0,01$ & $-0,06$ & $-0,13$ & $-0,08$ & - & - & - \\
Dezembro-Janeiro & - & $-0,34$ & $-0,42$ & $-0,53$ & $-0,39$ & - & - \\
Variação Total & 0,88 & $-0,35$ & $-1,94$ & $-1,96$ & $-1,68$ & $-0,74$ & 0,74 \\
Risco da Base & 0,51 & 0,61 & 0,66 & 0,57 & 0,44 & 0,21 & 0,43 \\
\hline
\end{tabular}

Fonte: Resultados da Pesquisa.

Quadro 5. Variações mensais da base (US\$/sc) em relação ao contrato futuro de soja da CBOT para a Região de Uberlândia com diferentes vencimentos. Média de 4 anos (2001 a 2004).

\begin{tabular}{|lccccccc|}
\hline \multicolumn{1}{|c}{ Meses } & \multicolumn{7}{c|}{ Contratos } \\
\cline { 2 - 8 } & Janeiro & Março & Maio & Julho & Agosto & Setembro & Novembro \\
\hline Janeiro-Fevereiro & - & $-1,01$ & $-1,01$ & $-0,95$ & $-0,96$ & $-0,59$ & - \\
Fevereiro-Março & - & - & $-0,42$ & $-0,46$ & $-0,40$ & $-0,20$ & - \\
Março-Abril & - & - & 0,00 & 0,00 & 0,09 & 0,31 & 0,12 \\
Abril-Maio & - & - & - & $-0,51$ & $-0,51$ & $-0,55$ & $-0,58$ \\
Maio-Junho & - & - & - & 0,13 & 0,16 & 0,12 & 0,05 \\
Junho-Julho & - & - & - & - & 0,22 & 0,20 & 0,11 \\
Julho-Agosto & - & - & - & - & - & $-0,05$ & $-0,19$ \\
Agosto-Setembro & $-0,05$ & - & - & - & - & - & 0,35 \\
Setembro-Outubro & 0,47 & 0,51 & - & - & - & - & 0,43 \\
Outubro-Novembro & 0,40 & 0,41 & 0,37 & 0,39 & - & - & - \\
Novembro-Dezembro & 0,08 & 0,03 & $-0,05$ & 0,02 & - & - & - \\
Dezembro-Janeiro & - & $-0,32$ & $-0,39$ & $-0,52$ & $-0,36$ & - & - \\
Variação Total & 0,91 & $-0,38$ & $-1,51$ & $-1,91$ & $-1,76$ & $-0,76$ & 0,29 \\
Risco da Base & 0,52 & 0,66 & 0,77 & 0,66 & 0,57 & 0,28 & 0,43 \\
\hline
\end{tabular}

Fonte: Resultados da Pesquisa. 


\subsubsection{Região de Cascavel}

O Quadro 8 apresenta as variações mensais do comportamento da base dos contratos de soja da CBOT para a região de Cascavel. Essa região apresenta retornos das estratégias de hedge na média do que foi encontrado para todas as regiões analisadas. Para operações de hedge de compra, o melhor contrato disponível é o de julho. Se utilizado entre os meses de novembro e maio, tem o potencial de retorno bruto de
US $\$ 2,24 / \mathrm{sc}$, associado a um risco de base de 0,82 . Os hedgers de venda, por sua vez, encontram o contrato de janeiro como sendo a melhor alternativa. No período de agosto a dezembro, retornaria US $\$ 0,80 / \mathrm{sc}$, com um risco de base de 0,78 .

\subsubsection{Região de Passo Fundo}

A região de Passo Fundo possui o comportamento da base, ao longo do ano, apresentado no Quadro 9. O

Quadro 6. Variações mensais da base (US\$/sc) em relação ao contrato futuro de soja da CBOT para a Região de Dourados com diferentes vencimentos. Média de 4 anos (2001 a 2004).

\begin{tabular}{|lccccccc|}
\hline \multicolumn{1}{|c}{ Meses } & \multicolumn{7}{c|}{ Contratos } \\
\cline { 2 - 8 } & Janeiro & Março & Maio & Julho & Agosto & Setembro & Novembro \\
\hline Janeiro-Fevereiro & - & $-1,01$ & $-1,00$ & $-0,94$ & $-0,95$ & $-0,67$ & - \\
Fevereiro-Março & - & - & $-0,41$ & $-0,45$ & $-0,39$ & $-0,18$ & - \\
Março-Abril & - & - & 0,32 & 0,31 & 0,40 & 0,61 & 0,24 \\
Abril-Maio & - & - & - & $-0,27$ & $-0,27$ & $-0,30$ & $-0,33$ \\
Maio-Junho & - & - & - & 0,18 & 0,21 & 0,17 & 0,11 \\
Junho-Julho & - & - & - & - & $-0,05$ & $-0,08$ & $-0,17$ \\
Julho-Agosto & - & - & - & - & - & 0,22 & 0,07 \\
Agosto-Setembro & 0,12 & - & - & - & - & - & 0,34 \\
Setembro-Outubro & 0,41 & 0,44 & - & - & - & - & 0,42 \\
Outubro-Novembro & 0,26 & 0,26 & 0,21 & 0,24 & - & - & - \\
Novembro-Dezembro & $-0,32$ & $-0,36$ & $-0,43$ & $-0,38$ & - & - & - \\
Dezembro-Janeiro & - & $-0,56$ & $-0,64$ & $-0,75$ & $-0,60$ & - & - \\
Variação Total & 0,48 & $-1,22$ & $-1,96$ & $-2,07$ & $-1,65$ & $-0,24$ & 0,68 \\
Risco da Base & 0,55 & 0,70 & 0,72 & 0,64 & 0,46 & 0,23 & 0,42 \\
\hline
\end{tabular}

Fonte: Resultados da Pesquisa.

Quadro 7. Variações mensais da base (US\$/sc) em relação ao contrato futuro de soja da CBOT para a Região de Cândido Mota com diferentes vencimentos. Média de 4 anos (2001 a 2004).

\begin{tabular}{|lccccccc|}
\hline \multicolumn{1}{|c}{ Meses } & \multicolumn{7}{c|}{ Contratos } \\
\cline { 2 - 8 } & Janeiro & Março & Maio & Julho & Agosto & Setembro & Novembro \\
\hline Janeiro-Fevereiro & - & $-1,09$ & $-1,09$ & $-1,03$ & $-1,04$ & $-0,67$ & - \\
Fevereiro-Março & - & - & $-0,62$ & $-0,66$ & $-0,60$ & $-0,40$ & - \\
Março-Abril & - & - & $-0,05$ & $-0,06$ & 0,03 & 0,25 & 0,07 \\
Abril-Maio & - & - & - & $-0,12$ & $-0,11$ & $-0,15$ & $-0,19$ \\
Maio-Junho & - & - & - & 0,55 & 0,24 & 0,19 & 0,14 \\
Junho-Julho & - & - & - & - & 0,10 & 0,07 & $-0,02$ \\
Julho-Agosto & - & - & - & - & - & 0,30 & 0,16 \\
Agosto-Setembro & 0,14 & - & - & - & - & - & 0,54 \\
Setembro-Outubro & 0,44 & 0,45 & - & - & - & - & 0,21 \\
Outubro-Novembro & 0,30 & 0,31 & 0,27 & 0,29 & - & - & - \\
Novembro-Dezembro & $-0,05$ & $-0,09$ & $-0,16$ & $-0,11$ & - & - & - \\
Dezembro-Janeiro & - & $-0,51$ & $-0,60$ & $-0,70$ & $-0,54$ & - & - \\
Variação Total & 0,84 & $-0,94$ & $-2,24$ & $-1,83$ & $-1,93$ & $-0,40$ & 0,90 \\
Risco da Base & 2,45 & 2,07 & 1,50 & 1,22 & 0,81 & 0,45 & 1,55 \\
\hline
\end{tabular}

Fonte: Resultados da Pesquisa. 
processo de enfraquecimento da base é bem intenso. Dentre as regiões estudadas, Passo Fundo apresenta o segundo maior retorno bruto (US\$ 2,56/sc). Esse retorno pode ser obtido utilizando-se o contrato de julho no intervalo dos meses de novembro a maio. O risco de base envolvido nessa estratégia é de 0,95. Aos hedgers de venda, as oportunidades se mostram bem reduzidas; praticamente as únicas alternativas disponíveis são os contratos de janeiro e novembro. Este último, se for mantida a posição vendida entre os meses de maio e outubro, pode oferecer um retorno bruto de US $\$ 0,90 / \mathrm{sc}$, e o risco de base de tal operação foi mensurado em 0,70 .

\subsubsection{Região de Chapecó}

O Quadro 10 mostra que as melhores oportunidades de hedge de compra na região de Chapecó são proporcionadas pelos contratos de maio (entre novembro e abril), julho (de novembro a maio) e agosto

Quadro 8. Variações mensais da base (US\$/sc) em relação ao contrato futuro de soja da CBOT para a Região de Cascavel com diferentes vencimentos. Média de 4 anos (2001 a 2004).

\begin{tabular}{|lccccccc|}
\hline \multicolumn{1}{|c}{ Meses } & \multicolumn{7}{c}{ Contratos } \\
\cline { 2 - 8 } & Janeiro & Março & Maio & Julho & Agosto & Setembro & Novembro \\
\hline Janeiro-Fevereiro & - & $-0,66$ & $-0,66$ & $-0,60$ & $-0,61$ & $-0,35$ & - \\
Fevereiro-Março & - & - & $-0,74$ & $-0,77$ & $-0,72$ & $-0,51$ & - \\
Março-Abril & - & - & $-0,07$ & $-0,08$ & 0,01 & 0,23 & $-0,04$ \\
Abril-Maio & - & - & - & $-0,24$ & $-0,24$ & $-0,27$ & $-0,31$ \\
Maio-Junho & - & - & - & 0,12 & 0,16 & 0,11 & 0,05 \\
Junho-Julho & - & - & - & - & 0,08 & 0,05 & $-0,03$ \\
Julho-Agosto & - & - & - & - & - & 0,15 & 0,00 \\
Agosto-Setembro & 0,17 & - & - & - & - & - & 0,49 \\
Setembro-Outubro & 0,37 & 0,37 & - & - & - & - & 0,16 \\
Outubro-Novembro & 0,26 & 0,26 & 0,22 & 0,25 & - & - & - \\
Novembro-Dezembro & 0,00 & $-0,04$ & $-0,11$ & $-0,06$ & - & - & - \\
Dezembro-Janeiro & - & $-0,29$ & $-0,37$ & $-0,48$ & $-0,33$ & - & - \\
Variação Total & 0,80 & $-0,36$ & $-1,73$ & $-1,87$ & $-1,64$ & $-0,59$ & 0,32 \\
Risco da Base & 0,78 & 0,96 & 0,91 & 0,76 & 0,57 & 0,39 & 0,88 \\
\hline
\end{tabular}

Fonte: Resultados da Pesquisa.

Quadro 9. Variações mensais da base (US\$/sc) em relação ao contrato futuro de soja da CBOT para a Região de Passo Fundo com diferentes vencimentos. Média de 4 anos (2001 a 2004).

\begin{tabular}{|lccccccc|}
\hline \multicolumn{1}{|c}{ Meses } & \multicolumn{9}{c}{ Contratos } & \multicolumn{3}{c|}{} \\
\cline { 2 - 8 } & Janeiro & Março & Maio & Julho & Agosto & Setembro & Novembro \\
\hline Janeiro-Fevereiro & - & $-0,73$ & $-0,73$ & $-0,67$ & $-0,68$ & $-0,51$ & - \\
Fevereiro-Março & - & - & $-0,51$ & $-0,55$ & $-0,49$ & $-0,29$ & - \\
Março-Abril & - & - & $-0,06$ & $-0,06$ & 0,02 & 0,24 & 0,09 \\
Abril-Maio & - & - & - & $-0,52$ & $-0,52$ & $-0,55$ & $-0,58$ \\
Maio-Junho & - & - & - & 0,22 & 0,25 & 0,21 & 0,15 \\
Junho-Julho & - & - & - & - & 0,13 & 0,11 & 0,01 \\
Julho-Agosto & - & - & - & - & - & 0,17 & 0,03 \\
Agosto-Setembro & 0,10 & - & - & - & - & - & 0,36 \\
Setembro-Outubro & 0,38 & 0,39 & - & - & - & - & 0,36 \\
Outubro-Novembro & 0,38 & 0,39 & 0,35 & 0,38 & - & - & - \\
Novembro-Dezembro & 0,01 & $-0,03$ & $-0,10$ & $-0,05$ & - & - & - \\
Dezembro-Janeiro & - & $-0,50$ & $-0,59$ & $-0,70$ & $-0,53$ & - & - \\
Variação Total & 0,88 & $-0,49$ & $-1,64$ & $-1,96$ & $-1,82$ & $-0,63$ & 0,41 \\
Risco da Base & 0,95 & 1,12 & 1,06 & 0,89 & 0,68 & 0,42 & 0,85 \\
\hline
\end{tabular}

Fonte: Resultados da Pesquisa. 
Quadro 10. Variações mensais da base (US\$/sc) em relação ao contrato futuro de soja da CBOT para a Região de Chapecó com diferentes vencimentos. Média de 4 anos (2001 a 2004).

\begin{tabular}{|lccccccc|}
\hline \multicolumn{1}{|c}{ Meses } & \multicolumn{7}{c|}{ Contratos } \\
\cline { 2 - 8 } & Janeiro & Março & Maio & Julho & Agosto & Setembro & Novembro \\
\hline Janeiro-Fevereiro & - & $-0,88$ & $-0,88$ & $-0,81$ & $-0,82$ & $-0,59$ & - \\
Fevereiro-Março & - & - & $-0,73$ & $-0,78$ & $-0,72$ & $-0,52$ & - \\
Março-Abril & - & - & $-0,06$ & $-0,07$ & 0,02 & 0,24 & 0,07 \\
Abril-Maio & - & - & - & $-0,35$ & $-0,34$ & $-0,38$ & $-0,41$ \\
Maio-Junho & - & - & - & 0,09 & 0,12 & 0,08 & 0,02 \\
Junho-Julho & - & - & - & - & 0,15 & 0,12 & 0,03 \\
Julho-Agosto & - & - & - & - & - & 0,22 & 0,08 \\
Agosto-Setembro & $-0,03$ & - & - & - & - & - & 0,39 \\
Setembro-Outubro & 0,46 & 0,47 & - & - & - & - & 0,27 \\
Outubro-Novembro & 0,25 & 0,26 & 0,24 & 0,26 & - & - & - \\
Novembro-Dezembro & $-0,04$ & $-0,09$ & $-0,16$ & $-0,11$ & - & - & - \\
Dezembro-Janeiro & - & $-0,04$ & $-0,12$ & $-0,23$ & $-0,07$ & - & - \\
Variação Total & 0,64 & $-0,28$ & $-1,72$ & $-2,00$ & $-1,66$ & $-0,82$ & 0,45 \\
Risco da Base & 1,25 & 1,55 & 1,34 & 1,06 & 0,81 & 0,59 & 1,32 \\
\hline
\end{tabular}

Fonte: Resultados da Pesquisa.

(de dezembro a maio). Novamente, o contrato de julho é o que apresenta maior retorno bruto, US\$ 2,35/ sc, com um risco de base de 1,17. Levando-se em consideração os resultados obtidos nas outras regiões, Chapecó possui boas e lucrativas oportunidades de gerenciamento de risco para agroindústrias e exportadoras. Repetidamente, a exemplo do que foi encontrado para outras regiões, as oportunidades de retornos brutos positivos para os hedgers de venda são bastante limitadas, sendo somente aptos a este tipo de estratégia os contratos de janeiro (entre setembro e novembro) e novembro (entre maio e outubro). Estes contratos podem retornar um ganho bruto de US $\$ 0,72 /$ sc e US $\$ 0,79 / \mathrm{sc}$, e o risco de base de 1,24 e 1,08 , respectivamente.

Na região de Chapecó, os riscos de base vão de 0,59 a 1,55 para os vencimentos de setembro e março, respectivamente. A diferença entre eles é de 2,63 vezes. Embora essa diferença esteja na média do que foi encontrado nas outras regiões, deve-se ressaltar que essa região apresentou os riscos de base maiores, mostrando que, para Chapecó, as informações passadas são menos seguras, quando comparadas as de outras regiões analisadas para o processo de tomada de decisão.

\subsection{Padrões de comportamento de base que permeiam as várias localidades}

A Figura 1 mostra por meio de uma ilustração (sem escala) que os períodos de enfraquecimento e fortalecimento das bases entre os preços à vista das várias regiões e as cotações dos contratos futuros da CBOT seguem padrões bem definidos ao longo do ano. Note que se trata apenas de uma ilustração que procura representar o padrão identificado nos resultados do item 5.1.

O comportamento identificado mostra que entre novembro e maio ter-se-ia o período de enfraquecimento da base. Durante esse intervalo de meses, este processo é bem intenso, sendo capaz de proporcionar bons retornos brutos aos hedgers de compra. Já entre os meses de maio e novembro, o comportamento da base dos diversos contratos da CBOT nas diversas regiões apresenta um movimento de fortalecimento.

Há também uma diferença quanto aos contratos que melhor se prestam para hedges de venda e de compra. No caso de hedge de venda, não existe um único vencimento que seja o melhor para todas as localidades, ao contrário do que ocorre no hedge de compra em que o contrato futuro com vencimento em julho é o melhor para todas as localidades.

Deve-se notar, no entanto, que, embora os períodos de enfraquecimento e fortalecimento da base possuam a mesma duração (6 meses), os retornos brutos proporcionados pelas diferentes estratégias não são equivalentes. As operações de hedge de venda proporcionam retornos consideravelmente menores que as operações de hedge de compra. Já o risco de base se mostrou maior para estratégias de hedge de compra. Ou seja, embora apresentassem maiores retornos brutos médios, as operações de hedge de compra seriam, em média, mais arriscadas do que as operações de hedge de venda. 


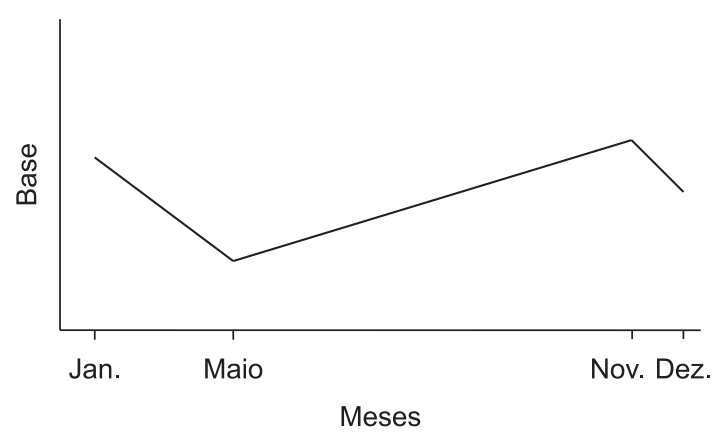

Figura 1. Representação do comportamento padrão da base em operações de hedge com contratos futuros de soja em grão da CBOT para as diversas regiões estudadas. Fonte: Resultados da Pesquisa.

\section{Conclusão}

Embora haja variações numéricas de região para região e de vencimento para vencimento do contrato futuro, a base entre os preços à vista no Brasil e as cotações a futuro da CBOT apresentam um padrão bastante definido: fortalecimento entre maio e novembro, seguido por enfraquecimento nos seis meses subsequentes. Isto sugere que, em média, operações de hedge de venda só devessem ser feitas entre os meses de maio e novembro, enquanto que operações de hedge de compra só deveriam ocorrer nos demais meses. Quanto aos melhores contratos para tais operações, no caso do hedge de venda, não há um padrão definido, embora os contratos com vencimentos em novembro e janeiro sejam os melhores para a maioria das regiões, mas no caso de hedge de compra, o contrato com vencimento em julho é o melhor para todas as regiões.

Embora o período de tempo em que as oportunidades de hedge de venda e de compra sejam de mesma duração (seis meses), os hedgers de compra possuem oportunidades de obter retornos brutos maiores devido ao processo de enfraquecimento da base ser mais intenso. Todavia, os riscos envolvidos nas estratégias de hedge de compra também são maiores, o que torna o retorno mais incerto.

Quanto ao risco de base de cada região, verificou-se que as regiões de Cândido Mota, Cascavel e de Passo Fundo apresentaram o contrato de março como sendo o de maior risco de base, enquanto as demais regiões ao norte do Brasil tiveram o contrato de maio como o mais arriscado. A discrepância entre os maiores e os menores riscos de base foi de aproximadamente três vezes. A região de Cândido Mota é a que inspira maiores cuidados na escolha do contrato, enquanto a região de Balsas apresentou uma maior homogeneidade de riscos entre os diferentes contratos. Foi identificado também que a região de Cândido Mota apresenta os valores de risco mais elevados, enquanto os menores valores foram encontrados na região de Sorriso. Por fim, salienta-se que os contratos de soja em grão da CBOT apresentam diferentes possibilidades de retornos brutos em função do tipo de hedge, do período hedgeado e do contrato utilizado. Por isso, as informações disponibilizadas neste trabalho se apresentam como importante subsídio ao processo de tomada de decisão por parte dos agentes da cadeia agroindustrial da soja.

\section{Referências}

AGUIAR, D. R. D. Agricultural futures contracts in Brazil: evolution and perspectives. In: MOURA, A. D.; SILVA Jr., A. G. (Eds.). Competitividade do Agronegócio Brasileiro em Mercados Globalizados. Viçosa: UFV, 2004.

BARCZSZ, S. S.; ALVES, A. F. A base da soja e seu comportamento para a região de Maringá no período de 1998-2000. In: CONGRESSO BRASILEIRO DE ECONOMIA E SOCIOLOGIA RURAL, 41., 2002, Aracajú. Anais... Brasília, DF: SOBER, 2002. p. 617-640.

BLANK, S.; CARTER, C. A.; SCHMIESING, B. H. Futures and options markets: trading in commodities and financials. Englewood Cliffs: Prentice-Hall, 1991. 410 p.

CARTER, C. A. Futures and options markets: an introduction. New Jersey: Upper Saddle River, 2003. $323 \mathrm{p}$.

CHIODI, L. et al. Análise da efetividade de hedging com contratos futuros na BM\&F e CBOT. In: CONGRESSO BRASILEIRO DE ECONOMIA E SOCIOLOGIA RURAL, 44., 2005, Ribeirão Preto. Anais... Riberão Preto, SP: CEARP/USP, 2005. 1 CD-ROM.

DIAS, V. C. F.; FIGUEIREDO NETO, L. F. Mercado futuro de soja na BM\&F e CBOT. In: CONGRESSO BRASILEIRO DE ECONOMIA E SOCIOLOGIA RURAL, 47., 2008, Rio Branco, AC. Anais... Brasília, DF: SOBER, 2008. 1 CD-ROM.

FILENI, D. H. O risco da base, a efetividade do hedging e um modelo para a estimativa da base: uma contribuição ao agronegócio de café em Minas Gerais. 1999. 137 f. Dissertação (Mestrado em Administração) - Universidade Federal de Lavras, Lavras, MG, 1999.

FONTES, R. E. et al. Estratégia de comercialização em mercados derivativos - descobrimento de base e de risco de base da cultura da soja em diversas localidades do Brasil. In: CONGRESSO BRASILEIRO DE ECONOMIA E SOCIOLOGIA RURAL, 44., 2005, Ribeirão Preto. Anais... Riberão Preto, SP: CEARP/ USP, 2005. 1 CD-ROM.

HOUTHAKKER, H. S.; WILliAMSON, P. J. The economics of financial markets. Oxford: Oxford University Press; New York: Hardcover, 1996. 361 p.

MARTINS, A. G; AGUIAR, D. R. D. Efetividade do Hedge de soja em grão brasileiro com contratos futuros de diferentes vencimentos na Chicago Board of Trade. Revista de Economia e Agronegócio, v. 2, n. 4 p. 449-472, 2004

SILVA, A. R. O; AGUIAR, D. R. D; LIMA, J. E. A efetividade do hedge e do cross-hedge de contratos futuros para soja e derivados. Revista de Economia e Sociologia Rural, v. 41, n. 2 p. 383-406, 2003. 